\title{
PREVALENCE OF HYPERTENSION AND ASSOCIATED RISK FACTORS AMONG ADULT RURAL WOMEN
}

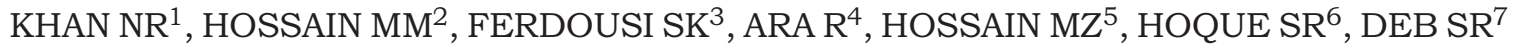

\begin{abstract}
:
The study was conducted among 393 respondents in the selected village of Sreepur upazilla of Gazipur district to find out the prevalence of hypertension and associated risk factors among adult rural women. The study was conducted from June to December 2009. In the study prevalence of hypertension was found $22.13 \%$ where $13.7 \%$ were known hypertensive and $8.42 \%$ were newly detected hypertensive patients, Out of 393 respondents, 31\% were found between the age group of 21-30 years where mean age was 36.36 years with $S D$ of \pm 12.68 years. Majority of the respondents were educated till primary school (39.2\%) and they were from poor socio-economic condition (42.7\%) i.e. monthly family income Tk. $<5000$. Most of them lived in a nuclear family (57\%). The majority of the respondents (66.4\%) had the habit of chewing betel nuts with jarda and 1.5\% were smokers. Out of 393 respondents $85.8 \%$ took extra salt in their diet. Among the extra salt intaker $85.05 \%$ were hypertensive and among the hypertensive respondents $34.48 \%$ had family history of hypertension and majority (31.03\%) were in the age group 31-40 years.
\end{abstract}

Key Words: Prevalence of Hypertension, risk factors, adult rural women.

J Dhaka Med Coll. 2011; 20(2) : 153-158.

\section{Introduction:}

Hypertension is a common health problem with sometimes devastating consequences and often remains asymptomatic until late in its course. ${ }^{1}$ It is a chronic, usually non-curable disorder. ${ }^{2}$ It is one of the most important risk factors for both coronary artery disease and cerebrovascular accidents. Hypertension can lead to cardiac hypertrophy, and potentially heart failure, aortic dissection and renal failure. Prevalence of hypertension in the developing countries seems to be similar to that in European or other technically developed societies ranging from 10 percent to as much as 20 percent among adults. ${ }^{3}$ Hypertension affects more than 800 million people worldwide. A sustained diastolic pressure greater than 90 $\mathrm{mm} \mathrm{Hg}$ or a sustained systolic pressure in excess of $140 \mathrm{~mm} \mathrm{Hg}$ is considered to constitute hypertension. ${ }^{1}$

The risk factor are thought to be dietary (particularly high levels of saturated fats and excess salts), lack of physical activity, obesity, psychosocial stress and smoking all of which arc identified with biological, hormonal and social changes. Furthermore, family history, age, sex, traffic noise, occupational stress, socioeconomic status and social stress are to be risks for the development of arterial hypertension. ${ }^{4}$ In more than $95 \%$ of cases, a specific underlying cause of hypertension cannot be found.' Such patients are said to have essential hypertension. ${ }^{5} \mathrm{~A}$ small number of

1. Dr. Nirmeen Rifat Khan, Assistant Professor, Department of Community Medicine, Dhaka Medical College, Dhaka.

2. Dr. Md. Moktel Hossain, Assistant Professor, Department of Community Medicine, Dhaka Medical College, Dhaka.

3. Dr. Syeda Khaleda Ferdousi, Assistant Professor, Department of Community Medicine, Dhaka Medical College, Dhaka.

4. Dr. Rowshan Ara, Assistant Professor, Department of Community Medicine, Dhaka Medical College, Dhaka.

5. Dr. Mohammad Zaid Hossain, Assistant Professor, Department of Medicine, Dhaka Medical College, Dhaka

6. Dr. Syeda Rumana Hoque, Medical Officer, Department of Community Medicine, Dhaka Medical College, Dhaka.

7. Dr. Sudip Ranjan Deb, Resident Physician, Dhaka Medical College Hospital, Dhaka.

Correspondence: Dr. Nirmeen Rifat Khan, Assistant Professor, Department of Community Medicine, Dhaka Medical College, Dhaka. Cell Phone:+8801720044255. 
patients (approximately 57\%) have underlying renal or adrenal disease (such as primary aldosteronism, cushing syndrome, pheochromocytoma), narrowing of the renal artery, usually by an atheromatous plaque (renovascular hypertension) or other identifiable cause (secondary hypertension). ${ }^{1}$ Hypertension is more common in some ethnic groups particularly Black Americans and Japanese, and approximately $40-60 \%$ is explained by genetic factors. ${ }^{5}$ The prevalence of hypertension among men and women is closely correlated with age. At age 35 a woman is only one third as likely to have high blood pressure and far better in her prognosis than a man of her same age. ${ }^{6}$ By age 65 , this gap evens out, with women running the same risk as men. ${ }^{7}$ Recently it has been recognized that women develop high blood pressure particularly systolic hypertension, at an increased rate as they age, and this age-related blood pressure increase is exaggerated by the menopause. ${ }^{8}$ Factors contributing to hypertension in postmenopausal women include changes in estrogen/ androgen ratios ovarian senescence, endothelial dysfunction, arterial stiffness, renin-angiotensin system activation, obesity etc. ${ }^{9}$ It is also possible that menopause might provide the environmental trigger for expression of certain genetic susceptibilities to hypertension which is a polygenetic disorder, with each of the genes contributing modestly to BP. ${ }^{9}$ Data from the American Heart Association Heart Disease and Stroke Statistics -2008 update shows that high blood pressure kills significantly more women than men and is two to three times more common in who take oral contraceptives than in women who don't. Gestational hypertension is the most common sign of preeclampsia. It is a serious medical condition affecting all organs of the body. ${ }^{10}$ Hypertension is an important cause of both maternal and fetal morbidity and mortality in pregnant women. ${ }^{11}$ About $6 \%$ of women with no history of high blood pressure will spontaneously develop high blood pressure during pregnancy. This is referred to as gestational hypertension. ${ }^{12}$ Pregnant women now develop de novo proteinuric hypertension (Pre eclampsia) can share many risk factors with patients with the metabolic syndrome such as obesity, dyslipidemia and insulin resistance. ${ }^{13}$ It may also be associated with convulsions (eclampsia) thrombocytopenia, hyperreflexia with clonus or both. ${ }^{14}$ It causes spontaneous abortion, intrauterine growth retardation, preterm delivery and low birth weight baby. Hypertension is directly responsible for $57 \%$ of all stroke deaths and $24 \%$ of all coronary heart disease deaths. This fact is important because hypertension is a controllable disease and a $2 \mathrm{~mm} \mathrm{Hg}$ populationwide decrease in BP can prevent 151,000 stroke $\& 1,53,000$ coronary heart disease deaths. ${ }^{15}$

The World Hypertension League (WHL) an umbrella organization of 85 national hypertension societies and leagues recognized that more than $50 \%$ of the hypertensive population worldwide is unaware of the condition. To address this problem, the WHL limited a global awareness campaign on hypertension in 2005 and dedicated May 17 of each year as World Hypertension Day (WHD). ${ }^{16}$ In Bangladesh there is no national epidemiological recording system for HTN. It was found in studies that $71.6 \%$ of rural and $86.3 \%$ of urban population were undetected and untreated for hypertension. ${ }^{17}$ Prevalence of hypertension in Bangladesh appears to be lower than in the industrialized countries of the world. Extensive surveillance for detection and treatment of hypertension would go a long way in prevention of its complication. ${ }^{18}$

The present study is aimed at determining the level of' blood pressure among the adult rural women in a selected rural community and associated factors in order to estimate the load of hypertension among women in our country. This study would help us to make future plan and to take necessary action to combat the problem.

\section{Materials and Methods:}

A cross sectional type of study was conducted at Khozekhani village of Ghosingha union of Sreepur Upazilla in Gazipur district during the period from June 2009 to December 2009. The sample size of the study was determined conveniently. The target population was all the adult women of Khozekhani village. Among 
them final sample size was 393 from whom data were collected. Purposive sampling technique was followed for colleting data through face to face interview based on structured questionnaire \& check list, which includes all the relevant information Blood pressure of the respondents, of objectives of the study and using relevant statistical tools and techniques. Results obtained were presented in tables graphs and charts. Simple statistical analysis was also done and presented with the result whenever necessary and possible.

\section{Result:}

A total number of 393 women participated in the observation. Majority of the respondents (31\%) were within $21-30$ years with a mean age of 36.36 years and standard deviation of \pm 12.68 years. Among them $99.7 \%$ were Muslim $\&$ only $0.3 \%$ was Hindu. About $90.8 \%$ women were married, followed by widow (5.9\%), unmarried $(2.5 \%)$ and the least $0.8 \%$ were found to be divorced. Majority received education up to primary level (39.2\%). 25.25\% received secondary level education. $7.1 \%$ respondents passed S.S.C \& $3.3 \%$ passed H.S.C, $1 \%$ was graduate $\&$ above. Among the rest $9.9 \%$ were illiterate. Regarding occupation most of the respondents were housewives (93.9\%) followed by service holder (2\%) garment worker $(0.5 \%)$, day labourers $(0.3 \%)$ \& others $(3.3 \%)$. The monthly family income of most of the respondents was below 5000 tk (42.7\%). The mean income was 8267.68 tk \& the standard deviation was $\pm 7287.041 \mathrm{tk})$. Regarding type of family $57 \%$ respondents had nuclear, $36.4 \%$ had joint $\& 6.6 \%$ had extended families. Among the respondents $66.4 \%$ had the habit of chewing betel leaves, nuts with jarda. Beside this we found women who had the habit of smoking $(1.5 \%)$ taking "sada pata" $(1.3 \%)$ and other habits (30.8\%). Anxiety contributes high blood pressure. Among the respondents 146 were suffering from anxiety which was $37.2 \%$ of the total respondents. 57 women were used to take high fatty meal $\&$ they were $14.5 \%$ of the total respondents. Among the 393 respondents 337 were habituated of taking extra salt during meal, which constitutes $85.8 \%$ of the total respondents. $3.8 \%$ women were suffering from cardiac diseases followed by diabetes $(2.5 \%)$, rheumatic fever (1.8\%), kidney diseases $(1.3 \%)$, mental disorder $(0.3 \%)$ ) others $(22.1 \%) .68 .2 \%$ women were not suffering from any other diseases. Total 183 women used oral contraceptive pill which $46.6 \%$ of the total study population. $20.4 \%$ women had positive history of hypertension $\& 17.8 \%$ women had no positive history among blood relatives. History of hypertension was unknown to $61.8 \%$ women. Considering blood pressure in sitting, standing and supine position prevalence of high systolic blood pressure was found among 9.4\% of the respondents. The highest $30.3 \%$ had systolic blood pressure between 111-120 mm of $\mathrm{Hg}$. Mean blood pressure was $119.28 \mathrm{~mm}$ of $\mathrm{Hg}$ with a standard deviation of $\pm 14.659 \mathrm{~mm}$ of $\mathrm{Hg}$. Among the respondents $7.90 \%$ had diastolic hypertension. The highest $40.5 \%$ had diastolic blood pressure between 71-80 $\mathrm{mm}$ of $\mathrm{Hg}$. Mean blood pressure was $75.43 \mathrm{~mm}$ of $\mathrm{Hg}$ with a standard deviation of $\pm 10.128 \mathrm{~mm}$ of $\mathrm{Hg}$. Among the respondents 54 women were diagnosed cases of hypertension, another 33 women were detected as hypertensive patients, who were completely unaware of their condition. A total 87 women out of 393 were suffering from different degree of hypertension. So prevalence rate was $22.13 \%$. Among the hypertensive respondents majority (31.03\%) were in the age group 31-40, followed by the age group 41-50 (28.74\%), 21-30 (16.09\%), 51-60 (13.79\%), 6170(5.74\%), 18-20 (3.44\%) \& 71-80 (1.14\%). Regarding relationship between hypertension $\&$ extra salt intake, among the 87 hypertensive

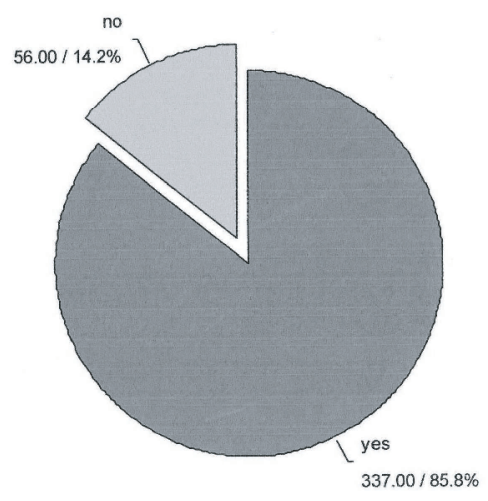

Fig.-1: Distribution of respondents according to extra salt intake 
respondents, 74 take extra salt during meal (85.05\%), Out of 87 hypertensive respondents $30(34.48 \%)$ had positive family history of hypertension whereas 44 (50.57\%) did not know about the family history of hypertension $\& 13$ (14.94\%) had no positive family history of hypertension.

Table-I

Distribution of the respondents by their age

\begin{tabular}{lcc}
\hline Age in Year & Frequency & Percentage \\
\hline$<20$ & 35 & 8.9 \\
$21-30$ & 122 & 31.0 \\
$31-40$ & 116 & 29.5 \\
$41-50$ & 71 & 18.1 \\
$51-60$ & 35 & 8.9 \\
$60+$ & 14 & 3.6 \\
\hline Total & 393 & 100.00 \\
\hline
\end{tabular}

Table-II

Distribution of the respondents according to prevalence of hypertension in different age groups

\begin{tabular}{lcc}
\hline Category of age & $\begin{array}{c}\text { Freguency of } \\
\text { hypertension }\end{array}$ & Percentage \\
\hline $18-20$ & 3 & 3.44 \\
$21-30$ & 14 & 16.091 \\
$31-40$ & 27 & 31.03 \\
$41-50$ & 25 & 28.74 \\
$51-60$ & 12 & 13.79 \\
$61-70$ & 5 & 5.74 \\
$71-80$ & 1 & 1.14 \\
\hline Total & 87 & 100 \\
\hline
\end{tabular}

\section{Discussion:}

In this study, among the respondents $87(22.13 \%)$ were found hypertensive. This prevalence is far grave than that showed by a study (a prevalence of $11 / 1000$ population having high blood pressure) which is mentioned in Rashid, Khabir, Hyder's textbook of Community Medicine and Public Health. ${ }^{18}$ This study shows $9.4 \%$ of the respondents had systolic hypertension whereas $7.9 \%$ of the respondents had diastolic hypertension. This is in contrast to the study done in rural population $(6.7 \%$ of the population had diastolic pressure equal to or greater than $90 \mathrm{~mm} \mathrm{Hg}$ demonstrated in the same book. ${ }^{18}$ Among the hypertensive respondents, $8.42 \%$ were completely unaware about their problem. This fact reveals the lack of knowledge about hypertension among our rural adult women.

Among the hypertensive respondents of this study majority $(31.03 \%)$ were in the age group $31--40$, followed by the age group 41-50 (28.74\%) revealing a picture which clearly differs from that of the study done by Jaipur Heart Watch (JHW) showing, age group 42-49 demonstrate a prevalence of $67 / 108$, compared to $22 / 148$ for people of 20-29 years age group. ${ }^{19}$ Among the 393 respondents, 337 were habituated of taking extra salt during meal, which constitutes $85.08 \%$ of the total respondents contributing much to the larger prevalence. This is just like that found in Japan where sodium intake was above $400 \mathrm{mmol}$ per day causing higher incidence of hypertension while primitive societies ingesting less than $60 \mathrm{mmol}$ per day have virtually no hypertension as mentioned in Park's Textbook of Preventive $\&$ Social Medicine. ${ }^{3}$ Another study done by Rosenthal T, Oparil S, it has been recognized that women develop high blood pressure, particularly systolic hypertension, at an increase rate as they age and this age - related blood pressure increase is exaggerated by the menopause. This contributes substantially to the age- related increase in risk of heart attack, heart failure, stroke in middle- aged and elderly women. ${ }^{8}$

Total 183 women used oral contraceptive pills which was $46.6 \%$ of the total study population forming a large portion of those who were hypertensive. This strengthens the data from the American Heart Association's Heart Disease and Stroke Statistics- 2008 Update showing that high blood pressure is 2-3 times more common in women who take oral contraceptives (OCP) than in women who do not. ${ }^{10}$

Among the respondents 146 (37.2\%) were suffering from anxiety contributing positively to high blood pressure. This supports the 
information given in the book Robbins \& Cotran Pathologic Basis of Disease that, stressful and competitive life style has contribution to raising blood pressure. ${ }^{1}$

Again 57 (14.5\%) women were used to take fatty meal making them vulnerable to hypertension and its deleterious effects. Majority of the respondents received education up to primary level $(39.2 \%)$ while monthly family income of most of the respondents were below $5000 \mathrm{Tk}$. According to Park's Textbook of Preventive \& Social Medicine, dietary habit of taking high saturated fat containing $\&$ low fiber containing food add to the risk of hypertension. Poor Socio-economic condition, gender discrimination, illiteracy, stresses to rural women both from family and environment make them more susceptible to hypertension. ${ }^{3}$

Among the respondents $66.4 \%$ had the habit of chewing betel leaves with jarda $\&$ nuts. Besides this we found women who had the habit of smoking $(1.5 \%)$, taking "sada pata" $(1.3 \%)$ or other habits (30.8\%). The study done in United Kingdom showing higher incidence of hypertension and its

hazards in smokers (i.e. eclampsia, low birth weight baby, death) indicates to their risk. ${ }^{3}$

Among 87 hypertensive respondents 30 $(34.48 \%)$ have positive family history of hypertension whereas $44(50.57 \%)$ do not know about the family history of hypertension. This is just the image of the family studies that have shown that the children of two normotensive parents have $3 \%$ possibility of developing hypertension. Where as this possibility is $45 \%$ in children of two hypertensive parents. ${ }^{3}$

$3.8 \%$ women were suffering from cardiac diseases, followed by diabetes $(2.5 \%)$, rheumatic fever $(1.8 \%)$, kidney diseases (1.3\%), mental disorder $(0.3 \%)$ and others $(22.1 \%) .68 .2 \%$ women were not suffering from any other diseases. This shows little similarity with the fact that hypertension can result from many systemic diseases like kidney diseases, endocrine dysfunctions, cardiovascular abnormalities, neurological disturbances and intake of drugs shown in Reid R, Roberts F, Pathology illustrated, $6^{\text {th }}$ edition. ${ }^{20}$

\section{Conclusion:}

With the increasing process of industrialization, urbanization and most importantly with the process of development non-communicable diseases like, hypertension can become a devastating problem for our country, if necessary precautionary steps are not taken in due time. So it is very important to realize the magnitude of the problem and the factors responsible behind it and take necessary actions to fight against it. A small study like this may not be so helpful for this purpose but it is obvious that this is not the end. This study can precede broader studies and research works which will certainly assist the government and general people to be more conscious about this disease of modern life.

\section{References:}

1. Schoen FJ. Robbins and Cotran Pathologic Basis of Disease. $7^{\text {th }}$ ed, 2008: 515-530

2. Grim RH, Flack JM, Granditis GA, Elmer PJ, Neaton JD, Cutler JA, etal, Long term effects on plasma lipids of diet and, drugs to treat hypertension, Journal of American Medical Association, May 22/29, 1996; 275 (20); 15491555 .

3. Park K. Epidemiology of Chronic Non Communicable Diseases, Park's Textbook of Preventive and Social Medicine, $19^{\text {th }}$ edition, February, 2007: 303-318.

4. Moneyki KD, Kemper HCG, The risk factors for elevated blood pressure and how to address cardiovascular risk factors, Journal of

Human Hypertension, April 17, 2008; 223, 450459.

5. Boon N A, Fox KAA, Bloomfield P. Disease of Cardiovascular System In: Hastelt Christopher, Chilvers Edwin R, Hunter John A A, Boon NA; 18 the edition. Davidson's Principle and Practice of Medicine, Churchill Livingstone (Harcourt Barce Co. Ltd): 24-28, Oval Road, London; 1999: 216-22, 357-482,608-615.

6. Fields L, Remme WJ. The burden of adult hypertension A rising tide. Hypertension 2004 ; 44 (4); 398-404.

7. Williams B, Poulter NR,Brown MJ et al (2004). Guidelines for management of hypertension: report of the fourth working party of the British Hypertension Society 2004- BHS IV. Journal of Human Hypertension. 18; 139-185 
8. Rosenthal T, Oparil S. Hypertension in Women, Journal of Human Hypertension, October 2000, volume 14: 691-704.

9. Coyleurisht M, Reckelhoff JF, Ouyang P. Menopause and hypertension. An age-old debate. Hypertension 2008; 51 ; 952-959.

10. American Heart Association, News releases, Journal edition dedicated to women's unique hypertension issues, September 52009.

11. Chung NAY, Beevers G, Lip GYH. Management of hypertension in pregnancy. Am . J Cardiovascular Drugs 2001; 1(4) ; 253-262.

12. Grossman K, Shur M, Jelic S, Gans S, Fugoros R, Gadi VK etal. High blood pressure during pregnancy. Hypertension 2007; 16 (4): 789-796.

13. Pipkin FB, Roberts JM. Hypertension in pregnancy. Journal of human hypertension 2000 ; 14 (10):705-724.
14. Brown MA, Buddle ML. Problems with the classification of hypertension in pregnancy. J Hypertens 1997; 15 1049-54.

15. Rodgers, A, Lawes, C and MacMahon, S, Reducing the global burden of blood pressure related cardiovascular disease. J. Hypertens, 2000, 18 (Suppl.1) S3-S6.

16. World hypertension League http//www. health.am/hyper/mass-media.

17. Islam $\mathrm{N}$, Khan $\mathrm{M}$, Latif ZA, Hypertension in the rural population of Bangladesh- A preliminary survey, Bangladesh Medical Research Council Bulletin, June 1983; ix (1):1 I--14

18. Rashid K M, Rahman M, Hyder S. Noncommunicable Diseases, Rashid, Khabir, Hyder's Textbook of Community Medicine and Public Health, $4^{\text {th }}$ edition, 2004: 276.

19. Gupta R, Gupta V P. Hypertension epidemiology in India: lessons From Jaipur Heart Watch. Current Science, volume97, August 2009.

20. Reid R, Roberts F, Pathology Illustrated, $6^{\text {th }}$ edition, 2006:197-199. 